\title{
Indo-Aryan Language
}

National Cancer Institute

\section{Source}

National Cancer Institute. Indo-Aryan Language. NCI Thesaurus. Code C161844.

A branch of Indo-Europen languages spoken on the Indian subcontinent. 